\title{
Ocular ischemic syndrome
}

\author{
Jia-Horung Hung MD, Yi-Sheng Chang MD PhD
}

- Cite as: CMAJ 2017 June 12;189:E804. doi: 10.1503/cmaj.160459

A 74-year-old man with hypertension and diabetes mellitus presented with a three-month history of intermittent orbital pain and progressive vision loss in his left eye, deteriorating to hand motions. The intraocular pressure was in the normal range at $13 \mathrm{~mm} \mathrm{Hg}$. Biomicroscopy showed prominent iris neovasculature (Figure $1 \mathrm{~A}$ ). Fluorescein angiography disclosed dot hemorrhages in the midperipheral retina, as well as delayed choroidal and retinal perfusion, indicating fundus ischemia. Intravitreal injection of bevacizumab, an anti-vascular endothelial growth factor agent, achieved rapid regression of iris neovasculature within six days (Figure 1B). For iris neovasculature without retinal vascular diseases, ocular ischemic syndrome should be considered, and total occlusion of the left internal carotid artery was shown on carotid duplex ultrasonography and angiography. Subsequent angioplasty with stenting restored the blood flow (see Appendix 1, available at www.cmaj.ca/lookup/suppl/doi:10.1503/ cmaj.160459/-/DC1). The patient has not had a recurrence of iris neovasculature and serial intraocular pressure measurements have not exceeded $20 \mathrm{~mm} \mathrm{Hg}$. At two-year follow-up, he was doing well, although his vision did not recover, because of the prolonged retinal ischemia.

Ocular ischemic syndrome is an uncommon but potentially blinding condition that results from severe ocular hypoperfusion. It may represent the first sign of carotid artery stenosis. The incidence rate is estimated to be 7.5 cases per million every year. ${ }^{1}$ Pain may be present in about $40 \%$ of cases. ${ }^{1}$ Careful examination of the anterior segment with a handheld ophthalmoscope may identify neovascularization of the iris, as it is observed in $87 \%$ of cases of this syndrome. ${ }^{2}$ Because the loss of vision is usually unilateral, ${ }^{1}$ examination findings for both eyes should be compared. Fundus fluorescein angiography, carotid duplex ultrasonography, cerebral angiog- raphy and magnetic resonance angiography may help in diagnosis. The overall mortality rate for patients with ocular ischemic syndrome is $40 \%$ at five years, most commonly from ischemic cardiovascular disease, followed by cerebrovascular disease. ${ }^{1}$

\section{References}

1. Mendrinos E, Machinis TG, Pournaras CJ. Ocular ischemic syndrome. Surv Ophthalmol 2010;55:2-34.

2. Mizener JB, Podhajsky P, Hayreh SS. Ocular ischemic syndrome. Ophthalmology 1997;104:859-64.

Clinical images are chosen because they are particularly intriguing, classic or dramatic. Submissions of clear, appropriately labelled high-resolution images must be accompanied by a figure caption. A brief explanation ( 300 words maximum) of the educational importance of the images with minimal references is required. The patient's written consent for publication must be obtained before submission.

\section{Competing interests: None declared.}

This article has been peer reviewed.

The authors have obtained patient consent.

Affiliations: Institute of Clinical Medicine (Hung), College of Medicine, National Cheng Kung University; Department of Ophthalmology (Hung, Chang), National Cheng Kung University Hospital, College of Medicine, National Cheng Kung University; Department of Ophthalmology (Chang), College of Medicine, National Cheng Kung University Tainan, Taiwan

Acknowledgements: The authors thank Drs. Chun-I Wu and Cheng-Han Lee (Department of Internal Medicine, National Cheng Kung University Hospital, College of Medicine, National Cheng Kung University) for conducting and interpreting the carotid angiography. We also thank Dr. Sung-Huei
Tseng (Department of Ophthalmology, College of Medicine, National Cheng Kung University, Tainan, Taiwan) and Dr. Chris J. Lin (Billings Clinic, Billings, MT, USA) for a critical reading of the manuscript. An earlier version of this work was presented at the 2015 spring meeting of The Ophthalmological Society of Taiwan.

Correspondence to: Yi-Sheng Chang, willis@mail.ncku.edu.tw 